\title{
Work-Associated Stress and Nicotine Dependence among Law Enforcement Personnel in Mangalore, India
}

\author{
R Priyanka1, Ashwini Rao*, Gururaghavendran Rajesh, Ramya Shenoy, BH \\ Mithun Pai
}

\begin{abstract}
Purpose: To investigate the work associated stress and nicotine dependence among law enforcement personnel in Mangalore, India. Materials and Methods: A cross-sectional questionnaire survey was conducted among law enforcement personnel in Mangalore, India. Demographic details, stress factors experienced at work and nicotine dependency were the variables studied. The extent of stress factors experienced at work was assessed using the Effort-Reward Imbalance scale (ERI). Nicotine dependence was measured using the Fagerström Test for Nicotine Dependence (FTND) and the Fagerström Test for Nicotine Dependence-Smokeless Tobacco (FTND-ST). Logistic regression was used for the statistical analysis. Results: Three hundred and four law enforcement personnel participated in the study, among whom 68 had the presence of one or more habits like tobacco smoking, tobacco chewing and alcohol use. The mean effort score was $15.8 \pm 4.10$ and the mean reward and mean overcommitment scores were $36.4 \pm 7.09$ and $17.8 \pm 5.32$ respectively. Effort/Reward ratio for the total participants was 1.0073 and for those with nicotine habit was $\mathbf{1 . 0 8 5 0}$. Results of our study demonstrated no significant association between domains of ERI scale and presence of habits but work associated stress was associated with the presence of one or more habits. Compared to constables, head constables had 1.12 times higher risk of having a nicotine habit. Conclusions: Our study implies job designation is associated with nicotine habits. However, there was no association between work associated stress and nicotine dependence among law enforcement personnel in Mangalore.
\end{abstract}

Keywords: Nicotine dependence - smoking - stress - law enforcement personnel - Mangalore

Asian Pac J Cancer Prev, 17 (2), 829-833

\section{Introduction}

Law enforcement is a diverse job and law enforcement officers are empowered not only with the responsibility of maintaining public order but they also have to engage with citizens, identify and solve problems, and also respond to tens of thousands of calls from the aggrieved. Each day presents new challenges that require application of their skills in new and different situations. The law enforcement officers or the police possess one of the most stressful occupations in the world today and are ranked among the top ten most stressful jobs in the world (Nicoara and Amelia, 2012).

Chronic work-related stress is recognized as an imbalance between high efforts spent and low rewards received, which can be calibrated using the effort-reward imbalance (ERI) questionnaire. ERI is a well-justified psychometric measure of work-related stress available for comparative socioepidemiologic investigations (Siegrist et al., 2004). The ERI model has been functionalised as a standardized self-report measure consisting of 22 Likert- scaled items. This model defines three unidimensional scales: 'effort', 'reward' and 'overcommitment' rated on a five-point Likert scale (Siegrist et al., 1996a).

Nicotine dependence and its degree of dependence are determined by a single or combination of factors like individual, genetic and psychosocial factors. Certain psychosocial factors like occupational stress and poor quality of life, might have an influence on the initiation and extent of smoking (Schmidt, 2010). The estimated number of hardcore adult smokers in the South-East Asian countries was 31.1 million, the absolute number of hardcore smokers was higher in India than Bangladesh and Thailand (Kishore et al., 2013). The strength of nicotine dependence can be determined by The Fagerstrom Test for Nicotine Dependence (FTND). It is an economical, non-invasive way to rapidly assess nicotine dependence. It helps the clinician determine the degree to which a patient is nicotine dependent (Fagerstrom et al., 1978). The Fagerstrom Test for Nicotine Dependence-Smokeless Tobacco (FTND-ST) is a modified form of Fagerstrom Test for Nicotine Dependence (FTND) used to find the 


\section{$R$ Priyanka et al}

degree of nicotine dependence among smokeless tobacco users (Ebbert et al., 2006). In India, tobacco consumption is both by smoked and smokeless forms, commonly used smoked forms are of beedis and cigarettes (Chandra et al., 2005). High levels of nicotine dependence among smokers could probably be due high levels of job stress, which may lead to difficulty in smoking cessation leading to cancer (Ota et al., 2004; Tanriover et al., 2013; Nakao et al., 2013).

Many people face stress in their professional or personal life, whereas law enforcement officers have high level of stress not only due of their nature of work, but also because of the environmental influences linked with their work (Nicoara and Amelia, 2012). These daily hassles coupled with their operational duties can have impacts on their health. Distress and other health problems might occur as a result of not coping with their serious operational duties (Berg et al., 2006). Degree of tobacco consumption might shed some light on potential stress at work (Siegrist et al., 2004).

Inspite of extensive literature search, we could not find any studies of work associated stress and Nicotine Dependence among law enforcement officers in India. Therefore this study was conceptualized to determine work associated Stress and nicotine dependence among law enforcement personnel in Mangalore, India

\section{Materials and Methods}

The study was conducted among law enforcement personnel in Mangalore, Dakshina Kannada district, which is located along the western coast of India. The study design was a cross-sectional type using a self-administered questionnaire. Data regarding age, gender, address, number of years in this occupation and tobacco consumption was collected from all participants. The Effort-Reward Imbalance (ERI) scale, a 22 item questionnaire: extrinsic efforts (5 items), occupational rewards (11 items), and overcommitment (6 items) (Siegrist et al., 1996a; Siegrist et al., 1996b) was used to measure stress. The Fagerström Test for Nicotine Dependence (Fagerstrom, 1978; Heatherton et al., 1991) and The Fagerström Test for Nicotine DependenceSmokeless Tobacco (FTND-ST) (Ebbert et al., 2006) were used to measure nicotine dependence. Ethical approval was obtained from the Institutional Ethics Committee (Protocol Ref No. 14057/2014). Translation and adaptation of the questionnaire to the local language (Kannada) was done using forward-translations and back-translations. The validity and reliability of the questionnaire was tested by a pilot study on 10 respondents who were representative of the study subjects but not included in the study $(\mathrm{k}=$ $0.85)$. Each participant was given 10 minutes time to fill the questionnaire. If any participant was not present in the first visit, a second visit was made.

\section{Statistical analysis}

The data was entered in the SPSS software (version 11.5) for statistical analysis. The analysis was done using one way analysis of variance (ANOVA) and Tukey

Table 1. Distribution of data and prevalence of habits

\begin{tabular}{|c|c|c|c|}
\hline & \multicolumn{2}{|c|}{ Prevalence of habits** } & \multirow[t]{2}{*}{ Total population } \\
\hline & YES & NO & \\
\hline Total population & $68(22.4)$ & $236(77.6)$ & 304 \\
\hline Tobacco smoking & $19(6.3)$ & $285(93.7)$ & 304 \\
\hline Tobacco chewing & $15(4.9)$ & $289(95.1)$ & 304 \\
\hline Alcohol & $58(19.1)$ & $246(80.9)$ & 304 \\
\hline \multicolumn{4}{|l|}{ Age } \\
\hline 20-29 years & $16(16.3)$ & $82(83.7)$ & $98(32.2)$ \\
\hline 30-39 years & $24(23.5)$ & $78(76.5)$ & $102(33.6)$ \\
\hline 40-49 years & $16(27.6)$ & $42(72.4)$ & $58(19.1)$ \\
\hline $50-59$ years & $12(26.1)$ & $34(73.9)$ & $46(15.1)$ \\
\hline \multicolumn{4}{|l|}{ Gender } \\
\hline Male & $67(26.1)$ & $190(73.9)$ & $257(84.5)$ \\
\hline Female & $1(2.1)$ & 46(97.9) & $47(15.5)$ \\
\hline \multicolumn{4}{|l|}{ Educational qualification } \\
\hline 10th standard or equivalent & $11(28.2)$ & $28(71.8)$ & $39(12.8)$ \\
\hline 12th standard or equivalent & $18(17.3)$ & $86(82.7)$ & $104(34.2)$ \\
\hline Diploma & $5(18.5)$ & $22(81.5)$ & $27(8.9)$ \\
\hline Undergraduate & $26(22.4)$ & $90(77.6)$ & $116(38.2)$ \\
\hline Post graduate & $8(44.4)$ & $10(55.6)$ & $18(5.9)$ \\
\hline \multicolumn{4}{|c|}{ Number of years in the occupation } \\
\hline Less than 10 years & $27(18.2)$ & $121(81.8)$ & $148(48.7)$ \\
\hline More than 10 years & $41(26.3)$ & $115(73.7)$ & $156(51.3)$ \\
\hline \multicolumn{4}{|l|}{ Job designation } \\
\hline Inspector & $2(33.3)$ & $4(66.7)$ & $6(1.9)$ \\
\hline Sub-inspector & $1(16.7)$ & $5(83.3)$ & $6(1.9)$ \\
\hline Assistant Sub-inspector & $5(21.7)$ & $18(78.3)$ & $23(7.5)$ \\
\hline Head constables & $17(32.1)$ & $36(67.9)$ & $53(17.4)$ \\
\hline Constables & 43(19.9) & $173(80.1)$ & $216(71.0)$ \\
\hline
\end{tabular}

*Figures in parenthesis represent percentages computed vertically for each group; **Figures in parenthesis represent percentages computed horizontally for each row 
Work-Associated Stress and Nicotine Dependence among Law Enforcement Personnel in Mangalore, India

post-hoc test. Multiple linear regression model for the dependent variable 'Habits present or absent' was fitted with the job designation, number of years in the occupation and for all the variables of Effort Reward Imbalance scale. Statistical significance was established at $\mathrm{p}<0.05$.

\section{Results}

Demographic data of the participants is given in Table 1. A total of 304 participants were included in the study and among them $66 \%$ were between $20-39$ years of age, $15.5 \%$ were females and $71 \%$ were constables. Presence of one or more habits like tobacco smoking and tobacco chewing were reported by $34(11.2 \%)$ participants, whereas $58(19.1 \%)$ reported the presence of alcohol habit. The prevalence of habit was found to be higher among males (26.1\%) compared to females $(2.1 \%)$ and also among those who had more than 10 years' experience in this profession (26.3\% Vs 18.2\%). Among the constables who formed $71 \%$ of the population, $43(19.9 \%)$ reported the presence of habit. Among the 19 who reported the smoking habit, 8 were head constables and 10 were constables and among the 15 who reported smokeless tobacco habit, 5 were head

Table 2. Mean Effort Reward Imbalance Score

\begin{tabular}{lcc}
\hline Variables & Habit present & Habit absent \\
\hline Effort score & $16.7 \pm 4.8$ & $37.0 \pm 7.0$ \\
Reward score & $34.2 \pm 6.6$ & $15.5 \pm 3.8$ \\
Overcommitment score & $18.9 \pm 4.9$ & $17.5 \pm 5.3$ \\
\hline
\end{tabular}

Table 3. Nicotine Dependence Based on FTND

\begin{tabular}{lc}
\hline Smoked tobacco & Smokeless tobacco \\
\hline No dependence - 0 & No dependence -0 \\
Low dependence $-53.8 \%$ & Low dependence -0 \\
Moderate dependence $-15.4 \%$ & Moderate dependence $-30 \%$ \\
High dependence $-30.8 \%$ & High dependence $-70 \%$ \\
\hline
\end{tabular}

constables and 7 were constables. (Table 1)

Mean Effort Reward Imbalance (ERI) scores and Effort Reward (ER) ratio of total population was found to be $66.11 \pm 12.28$ and 1.0073 respectively. The mean effort score was $15.83 \pm 4.10$, mean reward score was $36.44 \pm 7.09$ and mean over commitment score was found to be $17.84 \pm 5.32$. The ER ratio for those with nicotine habit was 1.0850 and for those without the nicotine habit was 0.9991 . For Effort Reward $(E R)=1$ the person reports one effort for one reward, for $\mathrm{ER}<1$ there are less efforts for each reward, and for ER $>1$ the person reports more efforts for each reward. The mean effort was more among those who had the absence of habit, but the mean reward and mean over commitment were more among those who had the presence of habit. (Table 2)

Based on the ERI model, along with the effort (workload or other job demands) put in by the employees, it the perceived imbalance between the efforts made and the reward received that leads to strain. Also, work that required high levels of effort but resulted in lower rewards could be the source of negative emotions in the subjects. This might be accompanied with continuous strain reactions (Siegrist et al., 2004).

When we calculated the nicotine dependence level based on FTND, we found that $53.8 \%$ of smoked tobacco users had low nicotine dependence and $30.8 \%$ had high nicotine dependence, whereas among smokeless tobacco users, $30 \%$ had moderate and $70 \%$ had high nicotine dependence. (Table 3)

When we compared demographic variables like age, education and number of years in the occupation, we found that although these variables were not significantly associated with the habit of smoking, tobacco chewing or alcohol consumption, job designation was found to be significantly associated with alcohol consumption. (Table 4)

The logistic regression model was constructed with habits as the dependent variable and job designation,

Table 4. Relationship between Demographic Variables and Habits

\begin{tabular}{|c|c|c|c|c|}
\hline \multirow[t]{2}{*}{ Variables } & Tobacco Smoking & Tobacco Chewing & Alcohol & ERI Scale \\
\hline & $\mathrm{p}$ value & $\mathrm{p}$ value & $\mathrm{p}$ value & $\mathrm{p}$ value \\
\hline Age & $\begin{array}{c}0.15 \\
r=0.3\end{array}$ & $\begin{array}{c}0.7 \\
r=-0.8\end{array}$ & $\begin{array}{c}0.1 \\
\mathrm{r}=0.2\end{array}$ & $\begin{array}{c}0.67 \\
r=-0.06\end{array}$ \\
\hline Education & 0.33 & 0.66 & 0.69 & 0.44 \\
\hline Number of years in the occupation & $\begin{array}{c}0.27 \\
r=0.2\end{array}$ & $\begin{array}{c}0.77 \\
r=-0.08\end{array}$ & $\begin{array}{c}0.16 \\
r=-0.20\end{array}$ & $\begin{array}{c}0.88 \\
r=-0.02\end{array}$ \\
\hline Job designation & 0.7 & 0.3 & $<.001 *$ & 0.3 \\
\hline
\end{tabular}

*Indicates significant at $5 \%$ level of significance $(\mathrm{p}<0.05)$

Table 5. Logistic regression model for nicotine habits present with job designation, years of experience and Effort Reward Imbalance Scale

\begin{tabular}{|c|c|c|c|c|c|}
\hline \multirow[t]{2}{*}{ Variables } & \multirow[t]{2}{*}{ Regression coefficient } & \multirow[t]{2}{*}{$P$ value } & \multirow[t]{2}{*}{ Odds ratio } & \multicolumn{2}{|c|}{$95 \% \mathrm{CI}$} \\
\hline & & & & Lower & Upper \\
\hline No. of years in the occupation & 0.11 & 0.895 & 5.45 & 0.2 & 5.99 \\
\hline $\begin{array}{l}\text { Job designation } \\
\text { (Constables and head constables) }\end{array}$ & 1.69 & $<.001 *$ & 1.12 & 1.55 & 19.08 \\
\hline ER ratio & -0.48 & 0.24 & 0.61 & 0.27 & 1.39 \\
\hline
\end{tabular}

*Significant at $5 \%$ level of significance $(\mathrm{p}<0.05)$ 
years of experience and Effort Reward Imbalance Scale as the independent variables. There was a significant relationship between nicotine habit and job designation among constables and head constables, but there was no significant difference among the other cadre like inspectors and sub-inspectors. Compared to constables, head constables had 1.12 times higher risk of having the nicotine habit. (Table 5)

\section{Discussion}

The present study tried to explore the work associated stress and nicotine dependence among law enforcement personnel in Mangalore, India.

The prevalence of tobacco smoking in our study was low $(6.3 \%)$ compared to other studies (Vitavasiri et al., 2009; Sujatha et al., 2012; Thakur et al., 2013; Hock et al., 2014; Alsanosy 2014). When we compared our findings with (Mallikarjun et al., 2014) that of a study done in the same geographic area among bus drivers, we found the prevalence of tobacco smoking to be very low in our group compared to the findings among bus drivers.

In our study we used the ERI scale to measure stress and found that the mean effort domain was higher among those who had no habit, but mean reward domain and mean overcommitment domain were higher among those who had the habit. Few studies (Siegrist et al., 1990; Bosma et al., 1998) have shown that cardiovascular health, subjective health, mild psychiatric disorders and other reported symptoms could be due to the risk factors like high effort and low reward at work.

In the present study the mean ERI score was $66.11 \pm 12.28$, which was found to be different from a previous study (Hunnur et al., 2014) on law enforcement personnel in 4 districts of Karnataka, which showed high stress with a mean score of 175.54. Previous studies (Head et al., 2004; Hintsa et al., 2015) have shown that ERI scale had an effect on alcohol dependence and also on cardiovascular disease risk. But in the present study there was no significant relation between overcommitment and habits like smoking, tobacco chewing and alcohol consumption which predispose to cardiovascular disease.

In the current study FTND and FTND-ST showed no significant association with ERI scale, as very few participants answered the nicotine dependence questionnaire. Thirty four participants reported the presence of tobacco habit, out of which 19 participants had habit of tobacco smoking and 15 participants had tobacco chewing habit. Among those who responded to FTND, 53.8\% had low nicotine dependence and 30.8\% had high nicotine dependence for tobacco smoking and among those responded to FTND-ST 30\% had moderate and $70 \%$ had high dependence for smokeless tobacco.

Although, in the present study overall ERI scale did not show any significant relation with nicotine dependence, individual domains of effort and reward had shown significant relation with habits like smoking, tobacco chewing and alcohol consumption. In contrast to present study other studies (Garbarino et al., 2013; Kouvonen et al., 2005) have shown an association between work stress and smoking. However these studies were conducted among special force police officers in Italy and in public sector employees, who had a different life style and work load. The findings of the present study are similar to the data form the Cologne Smoking Study (Schmidt et al., 2010) which did not show any association between job stress and nicotine dependence using FTND and ERI scales.

Job designation was significantly associated with alcohol consumption, but it did not show any relation with smoking, tobacco chewing and ERI scale. The main limitation of the present study is that of a potential bias due to non-response (response rate of $76 \%$ ), as with any population based survey. However, the participants are representative of all members of the law enforcement personal in Mangalore.

In conclusion, our study shows that although job designation is associated with habits, it is not associated with nicotine dependency. An inherent limitation with any questionnaire study design, that the respondents may not tell the truth due to social desirability or regulatory obligations also needs to be considered.

\section{References}

Alsanosy RM (2014). Smokeless tobacco (shammah) in Saudi Arabia: a review of its pattern of use, prevalence, and potential role in oral cancer. Asian Pac J Cancer Prev, 15, 6477-83.

Berg AM, Hem E, Lau B, Ekeberg O (2006). An exploration of job stress and health in the Norwegian police service: a cross sectional study. J Occup Med Toxicol, 1, 26.

Bosma H, Peter R, Siegrist J, Marmot M (1998). Two alternative job stress models and the risk of coronary heart disease. Am J Public Health, 88, 68-74.

Chandra PS, Carey MP, Carey KB, et al (2005). Prevalence and Correlates of Tobacco Use and Nicotine Dependence among Psychiatric Patients in India. Addict Behav, 30, 1290-9.

Ebbert JO, Patten CA, Schroeder DR (2006). The Fagerström Test for Nicotine Dependence-Smokeless Tobacco (FTNDST). Addict Behav, 31, 1716-21.

Fagerstrom KO, Heatherton TF, Kozlowski LT (1990). Nicotine Addiction and Its Assessment. Ear Nose Throat J, 69, 763-5.

Garbarino S, Cuomo G, Chiorri C, Magnavita N (2013). Association of work-related stress with mental health problems in a special police force unit. BMJ Open, 3, 2791.

Gershon RRM, Lin S, Li X (2002). Work stress in aging police officer. JOEM, 44, 160-7.

Guo H, Yang W, Cao Y, Li J and Siegrist J (2014). Effort-reward imbalance at school and depressive symptoms in chinese adolescents: the role of family socioeconomic status. Int $J$ Environ Res Public Health, 11, 6085-98.

Head J, Stansfeld SA, Siegrist J (2004). The psychosocial work environment and alcohol dependence: a prospective study. Occup Environ Med, 61, 219-24.

Heatherton TF, Kozlowski LT, Frecker RC, Fagerstrom KO (1991). The Fagerstrom Test for Nicotine Dependence: a revision of the Fagerstrom Tolerance Questionnaire. $\mathrm{Br} J$ Addict, 86, 1119-27.

Hintsa T, Kouvonen A, McCann M, et al (2015). Higher effortreward imbalance and lower job control predict exit from the labour market at the age of 61 years or younger: Evidence from the English Longitudinal Study of Ageing. J Epidemiol Community Health, 69, 543-9.

Hock LK, Ghazali SM, Cheong KC, et al (2014). Prevalence and factors associated with smoking intentions among non- 
smoking and smoking adolescents in Kota Tinggi, Johor, Malaysia. Asian Pac J Cancer Prev, 15, 4359-66.

Hunnur RR, Bagali MM, Sudarshan S (2014). Cause and effect of workplace stress among police personnel: An Empirical Study. Int J Mgmt Res Bus Strat, 3, 199-208.

Kishore J, Jena PK, Bandyopadhyay C, et al (2013). Hardcore smoking in three South-East asian countries: results from the global adult tobacco survey. Asian Pac J Cancer Prev, 14, 625-30.

Kouvonen A, Kivimaki M, Virtanen M, Pentti J, Vahtera J (2005). Work stress, smoking status, and smoking intensity: an observational study of 46190 employees. J Epidemiol Community Health, 59, 63-9.

Lau B (2008). Effort-reward imbalance and overcommitment in employees in a Norwegian municipality: a cross sectional study. J Occup Med Toxicol, 3, 1-11.

Limm H, Angerer P, Heinmueller M, et al (2010). Self-perceived stress reactivity is an indicator of psychosocial impairment at the workplace. BMC Public Health, 10, 252.

Liu C, Wang L, Zhao Q (2015). Factors related to health-related quality of life among Chinese psychiatrists: occupational stress and psychological capital. BMC Health Serv Res, $15,20$.

Mallikarjun S, Rao A, Rajesh G, Shenoy R, Pai MBH (2014). Role of Tobacco Warning Labels in informing smokers about risks of smoking among bus drivers in Mangalore, India. Asian Pac J Cancer Prev, 15, 8265-70.

Nakao M, Hosono S, Ito H, et al (2013). Cigarette smoking and pancreatic cancer risk: a revisit with an assessment of the nicotine dependence phenotype. Asian Pac J Cancer Prev, 14, 4409-13.

Nicoara P,Amelia VL (2012). Burnout - an effect of professional stress in the police environment. 2nd international conference on economics, Trade Development IPEDR, $\mathbf{3 6}$.

Ota A, Yasuda N, Okamoto Y, et al (2004). Relationship of job stress and nicotine dependence of smokers. -a cross sectional study of female nurses in a general hospital.J Occup Health, 46, 220-4.

Schmidt A, Neumann M, Wirtz M, et al (2010). The influence of occupational stress factors on the nicotine dependence: a cross sectional study. Tob Induc Dis, $\mathbf{8}, 6$.

Siegrist J, Peter R, Junge A, Cremer P, Seidel D (1990). Low status control, high effort at work and ischemic heart disease: Prospective evidence from bluecollar men. Soc Sci Med, 31, 1127-34.

Siegrist J (1996a). Adverse health effects of high-effort/lowreward conditions. J Occup Health Psychol, 1, 27-41.

Siegrist J (1996b). Adverse health effects of high-effort/ low reward conditions. Journal of Occupational Health Psychology. J Occup Health Psychol, 1, 27-41.

Siegrist J, Starke D, Chandola T, et al (2004). The measurement of effort-reward imbalance at work: European comparisons. Soc Sci Med, 58, 1483-99.

Sujatha D, Hebbar PB, Pai A (2012). Prevalence and correlation of oral lesions among tobacco smokers, tobacco chewers, areca nut and alcohol users. Asian Pacific J Cancer Prev, 13, 1633-7.

Tanriover O, Karamustafalioglu N, Tezvaran Z, Kaplan A, Tomruk N (2013). Frequency of cigarette smoking among psychiatric inpatients evaluated by the fagerström test for nicotine dependence. Asian Pac J Cancer Prev, 14, 579-82.

Thakur JS, Prinja S, Bhatnagar N, Rana S, Sinha DN (2013). Socioeconomic inequality in the prevalence of smoking and smokeless tobacco use in India. Asian Pac J Cancer Prev, 14, 6965-9.

Vitavasiri C, Pausawasdi S (2009). National survey on smoking situation in Royal Thai Police. J Med Assoc Thai, 920,
1361-6. 